\title{
Cowden's disease manifested by esophageal polyp- osis with characteristic appearance on magnifying endoscopy using narrow band imaging
}

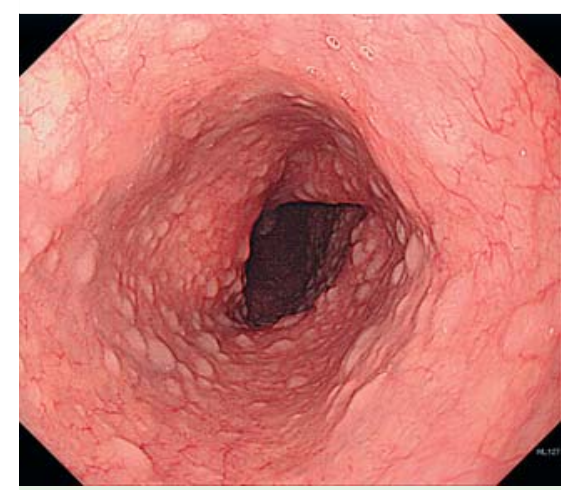

Fig. 1 Upper gastrointestinal endoscopy showed multiple small whitish lesions in the esophagus.

Cowden's disease is characterized by hyperplastic lesions and hamartomas distributed throughout the body, including cutaneous facial papules, oral mucosal lesions, and gastrointestinal polyposis [1]. Cowden's disease is known to be associated with malignancies such as breast cancer, thyroid carcinoma, and endometrial

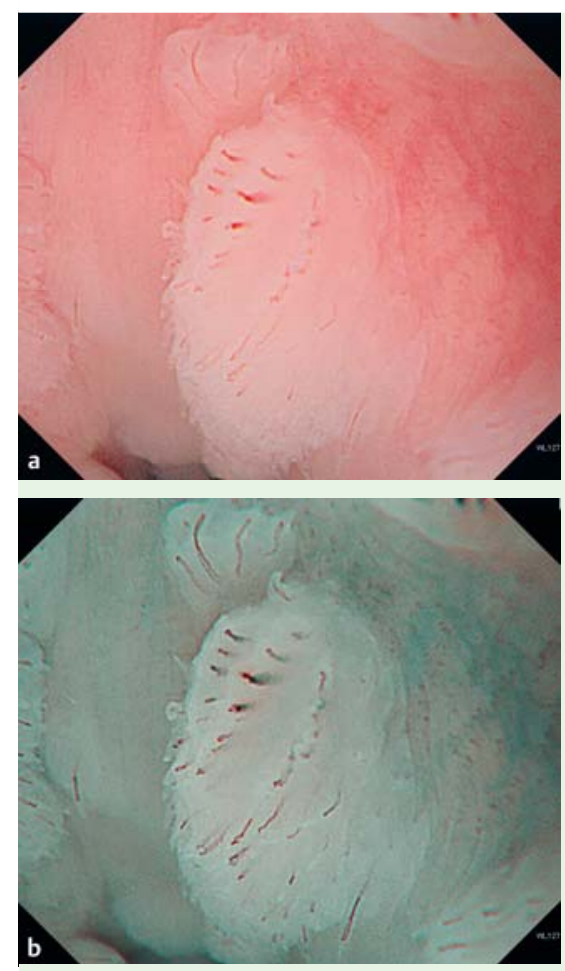

Fig. 2 a-d Magnifying endoscopy showed whitish lesions with reddish tentacles $(\mathbf{a}, \mathbf{c})$, and magnifying endoscopy with narrowband imaging carcinoma. We report a rare case of Cowden's disease manifested by esophageal polyposis with a characteristic appearance on magnifying endoscopic using narrow band imaging (NBI).

A 36-year-old man underwent upper gastrointestinal endoscopy for a health check-up. Multiple polypoid lesions were seen in the esophagus, stomach, and duodenum. The esophageal polyposis showed multiple small whitish lesions ( $\bullet$ Fig. 1 ). Magnifying endoscopy showed whitish lesions with reddish tentacles ( $\bullet$ Fig. 2 a,c), and magnifying endoscopy with NBI (ME$\mathrm{NBI}$ ) revealed that each tentacle represented a highly extended microvessel (intrapapillary capillary loop) ( Fig. $\mathbf{2 b}, \mathbf{d}$ ), giving a resemblance to dragon fruit. Histopathologic analysis of endoscopic biopsy specimens taken from the esophageal and gastric lesions showed glycogenic acanthosis and hyperplastic polyps, respectively. The patient had multiple cutaneous papules of the face, mouth, and fingers. Histopathologic analysis of the

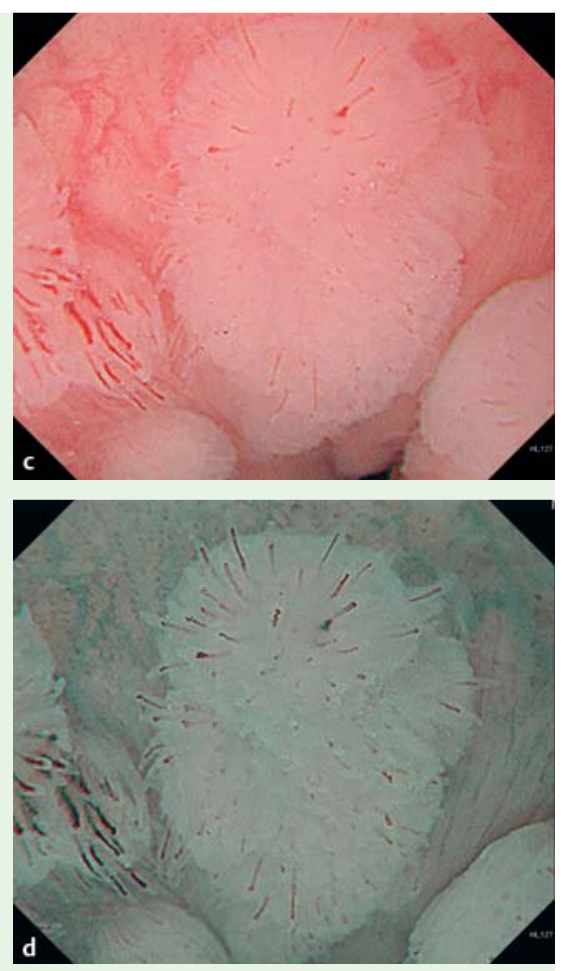

revealed that each tentacle represented a highly extended microvessel (intrapapillary capillary loop) $(\mathbf{b}, \mathbf{d})$, giving a resemblance to dragon fruit. skin excisional biopsy showed hamartomatous changes. Ultrasonography revealed small thyroid lesions. Abdominal CT showed no abnormalities.

The patient was therefore diagnosed as having Cowden's disease without malignancy, manifested by pathognomonic gastrointestinal and mucocutaneous lesions. In this case, the gastrointestinal polyposis gave the initial opportunity for the diagnosis, and the endoscopic appearance of the esophageal polyposis on ME-NBI was impressive and interesting. Because malignant tumors have been reported as a complication in about $30 \%$ of patients with Cowden's disease, early diagnosis of the disease is necessary. Such a characteristic endoscopic finding on ME-NBI would be useful for early diagnosis of Cowden's disease.

Endoscopy_UCTN_Code_CCL_1AB_2AC_3AB

Competing interests: None

D. Norimura ${ }^{1}$, H. Isomoto ${ }^{2}$, E. Fukuda ${ }^{1}$, T. Yamao' , E. Ozawa', K. Iwasaki ${ }^{3}$, K. Ohnita ${ }^{2}$, F. Takeshima², S. Shikuwa², K. Nakao ${ }^{2}$

${ }^{1}$ Department of Gastroenterology and Hepatology, Sasebo Municipal General Hospital, Sasebo, Japan

2 Department of Gastroenterology and Hepatology, Nagasaki University Hospital, Nagasaki, Japan

${ }^{3}$ Department of Pathology, Sasebo Municipal General Hospital, Sasebo, Japan

\section{References}

1 Umemura K, Takagi S, Ishigaki Yet al. Gastrointestinal polyposis with esophageal polyposis is useful for early diagnosis of Cowden's disease. World J Gastroenterol 2008; 14 : 5755-5759

\section{Bibliography}

Dol http://dx.doi.org/

10.1055/s-0032-1310022

Endoscopy 2013; 45: E298

(c) Georg Thieme Verlag KG

Stuttgart · New York

ISSN 0013-726X

Corresponding author

\section{Norimura, MD}

Sasebo Municipal General Hospital

9-3 Hirase, Sasebo

857-8511 Japan

Fax: +81-95-6224641

norir333081@yahoo.co.jp 